\title{
The Analysis of Flipped Classroom Mode of CIMA Financial Operation Course
}

\author{
Yuanyuan Zhao ${ }^{1, a^{*}}$, Xiuyuan Deng ${ }^{2, b^{*}}$ and Shen Zhai ${ }^{1, c}$ \\ ${ }^{1}$ Chengdu Neusoft University, Du Jiangyan, Sichuan, China \\ ${ }^{2}$ Chongqing University of Technology, Chongqing, China \\ a*ZhaoYuanyuan@nsu.edu.cn, ${ }^{\mathrm{b}} 43406789 @ q q . c o m,{ }^{\mathrm{c}}$ zhais@hotmail.com
}

\section{Keywords: Flipped classroom; CIMA course; Financial operation; Teaching paradigms}

\begin{abstract}
Flipped classroom depends on the development of information technology and innovative teaching concepts. It reverses time and space of teaching and learning of traditional classroom and induces deep reform of teaching concepts, teaching objectives, teaching methods and interactive mechanism, etc. The thesis puts forward the construction of new teaching model on the basis of having discussed good connection between flipped classroom and CIMA financial operation course. The model is based on basic framework of three design modules of "pre-class - related-post-lecture". It hopes to improve inherent problems of traditional teaching paradigms. It hopes to provide ideas and directions to construct high-effective classroom. It also hopes to promote teaching reform of CIMA course in universities.
\end{abstract}

\section{Introduction}

CIMA (The Chartered Institute of Management Accountants) is the largest international organization of management accountant in the world. It provides international authority professional finance certification in the field of finance management and strategic decision. CIMA course system of universities complements advantages of Chinese higher education and international vocational education of management accounting. It highlights international teaching concepts, hierarchical teaching framework, and practical teaching contents. It also helps to improve relatively lagging position of the development of Chinese management accounting. Financial operation is an examination subject of CIMA course system (it is divided into four stages including foundation stage, operation stage, management and strategy stage) in the operation stage. It covers the contents including IAS, taxation, financial reports and regulatory policies, etc. Particularly, it focuses on comprehensive application of knowledge and case analysis. However, class teaching paradigms of "teaching in class + homework after classes on comprehensive application of knowledge and case analysis. However, class teaching paradigms of "teaching in tion is an examination subject of CIMA course system etc. Flipping Classroom is a new paradigm of B-Learning [1]. It integrates information technology with innovative teaching concepts. It also provides ideas and directions to promote teaching reform of finance operation course and construct high-effective classroom.

\section{Flipping Classroom Based on the Innovative Teaching Paradigm of the Constructivism}

Flipping Classroom (can be translated aching Paradigm of $\mathrm{t}$ ) has been a new teaching paradigm recently. It has been praised highly by international education. This paradigm uses elements including "situation", "cooperation", can be translate etc. to make a full play of student's entity. It can reverse teaching process: with the help of information technology, teachers provide study resources of the main form of teaching videos and students completed watching and learning study resources before the class. It achieves the part of teaching knowledge. The process of knowledge internalization is completed by teachers and students together take part in the activities including homework question-answering, case analysis and interaction, etc. in the class. 


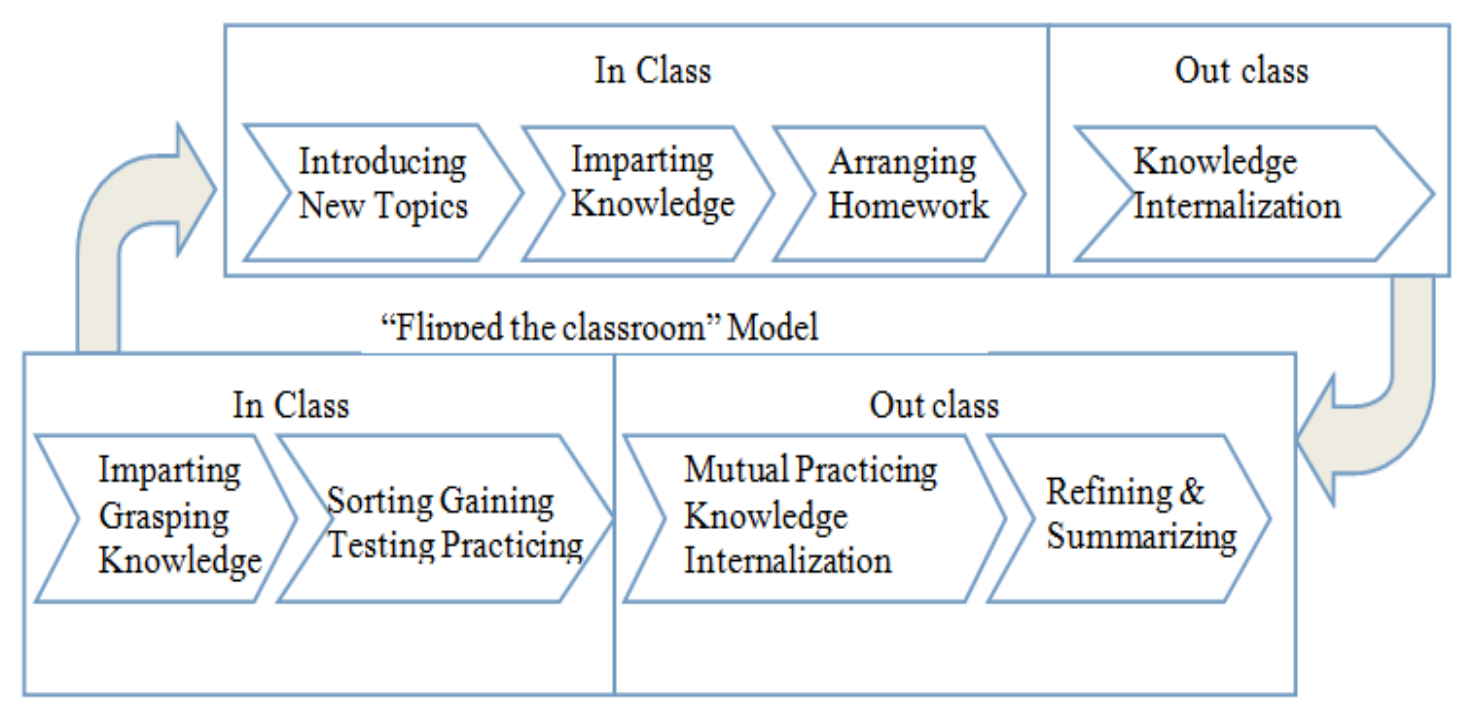

Figure 1. A comparison between traditional classroom and flipping classroom

It is not simple that Flipping classroom reverse the teaching sequence of traditional classroom. Flipping classroom is the B-Learning. It integrates face to face, traditional classroom with online teaching. Flipping classroom can induce all-around reform of teaching concepts, teaching methods and interaction mechanism, etc. Firstly, Flipping classroom changes the role of both teachers and students. Teachers transform knowledge initiators and classroom administrators into advisors and facilitators of learning while students transform passive receivers of learning into active students [2].The teaching concept of classroom administrators into advisors and facilitators of learning while students transform passive receivers of learning between teachers and students [3]. Secondly, Flipping classroom can promote effective use and R\&D of teaching resources. With the help of

"teaching resources" videos recorded by Khan Academy and "MOOCs" open online courses, Flipping classroom collects widely various information resources about the teaching on the Internet. It also makes the secondary deep processing of teaching information to build the network platform for learning of the students. Thirdly, Flipping classroom induces strengthen teacher-student interaction mechanism and deepen interaction hierarchy. It discards tradtional "teachers-students" and one-way "force-feeding" teaching methods. The students on flipping and students in the process of teaching. More communication between teachers and students enables teachers to provide specific guiding and assisting with students [4]. It can promote the development of individualized learning among students.

\section{The Analysis of Connection between Flipped Classroom and CIMA Financial Operation Course}

Financial operation course is aim to prepare financial statements (including balance sheets, profit statement, etc.) of an independent business and consolidated statements (100\% stake) of business group. It is supported by three aspects: principles of taxation (UK taxation), financial reports and regulatory policies (audit included) and professional ethics, IAS. It has the characteristics of interdisciplinary, timeliness, abstraction and logical regularity of the knowledge, etc. It also requires the students mastering basic theory and practical operation of courses [5]. The good connection between characteristics of financial operation course and teaching model of flipped classroom makes more feasibility of the assumption of improving the teaching effect.

The Connection of Teaching Objectives: Learning for Mastery of Gradient Teaching Mode. Teachers should divide hierarchy (gradient) of the students according to their cognitive levels and the development of two contexts [6]. The application of Flipping classroom just meets the need of gradient teaching: after class, the students of different gradients can independently measure progress of teaching videos, consult background information (there are too many background 
information of UK tax in particular) and master self-paced learning. In class, the students should integrate into free real, cooperative and high-involved learning environment. Self-teaching learning system is interweaved with deep interaction mechanism to improve effectively overall learning efficiency.

The Connection of Teaching Methods: Exploring a variety of basic forms of the practice teaching. In 2014, the new syllabus of CIMA has determined the " $3+1$ " mode (as the three major modules like the finance, the company and the performance, with the addition of the case study). The " $3+1$ "mode has highlighted the important position of case study in the curriculum system [7]. Using the flipped class model, students can watch the video before class. The video is about the business activities of the enterprise. Then students will organize some cases to discuss in class. The discussion combines with the basic practice teaching modes, like the interactive assignment teaching mode, the simulation teaching, and the project-based learning. Compared with the traditional class to accept the theories, it is easier to accept knowledge and better to complete the internalization of knowledge [8].

The Connection of Assessment Methods: Constructing the All-Around, Multidimensional and Three-Dimensional System of Evaluation. The assessment method of the flipped class model has its scientificity. It has the scientificity to evaluate the students' mastery on financial operation course. The financial operation course takes the global examination as its goal. The school examination should not be repeated use (paper) testing method to evaluate the students. To structure the new valuation criterion of the assessment method. The valuation criterion as the main part of teachers, partners, and personal, also combines with the test and the show of operation, the case study and the course paper. The standard is more conducive for the teacher to make a scientific and reasonable evaluation of the students' theoretical knowledge, practical ability, and the overall quality.

\section{The Teaching Design of the CIMA Financial Operation Course Based on the Flipped Classroom}

The teaching of the financial operation course is based on flipped class model. It requests the teacher to do reasonable arrangement of the two parts like "the pre-class", "The while-class" and base on the in-depth analysis of teaching goals and students' characteristics. The teacher should use the micro-test as the linking of the two parts, to construct a new mode of financial operation course teaching with the structure of "dumbbell" type [1].

The Module of Pre-Class Design: Founding a Resource System of Personalized Learning Combined with the Dynamic and Static Method. The first step of the pre-class design is to set the teaching task according to the teaching objectives. Due to bilingualism characteristic and the complexity of financial operation course. The teaching task requires planning the content of the two parts reasonably. The one is the static course: it raises the professional concept as the text or the PPT that the students need to master in each lesson. (it all bases on English); and another is the dynamic course: it is the video teaching(within 10-15 minutes). Teachers should divide the course sections into several units first, then to organize the knowledge points from the unit as the micro-video [9]. To do the example as the chapter named "Consolidated Statement of Financial Position", the course content can be divided into three units, and each unit could be subdivided into three or four points. It is very convenient for students to study autonomously. It has the intrinsic logic between each unit, and put all the units together it will return to a complete chapter.

The Module of Linking: The micro-test of the CIMA. Micro-test links the learning of pre-class and the activities of while-class; it plays an important role in connecting. The micro-test relates to the communication of teachers and students, and even relates to the smooth operation of the flip class. Students through the analysis the results of the test to find out their individual "blind area" of knowledge, and then to use resources to depth review the learning content of the pre-class; Teachers can understand most of the students' weaknesses and the situations of knowledge according to the results. Then teachers can arrange the lessons for answering the doubts. 
The Module of Lesson Design: The exploration of Practice Teaching with the Topic of "Student-Oriented". In the foundation of the students independently complete the knowledge, the class activities of the financial operation bases on the four basic process "lead-in - topic research assessment - feedback Summarize" , and discusses around the theme of "the topic research" . The topic research of class includes the four forms about the classwork, the problem-based learning and the interactive teaching and one-to-one personalized guidance. In practical application, it needs to balance students independent exploration with teamwork. It depends on the content of the course to choose the form. Still example of the chapter named Consolidated Statement of Financial Position:

The first unit is the combination of the basic concepts. This part requires the students to understand the three basic concepts and master the compilation process of the Standard Consolidated Statement of Financial Position. The whole unit is based on the text description, and the method of classwork can deepen the students' understanding and memory of knowledge.

The second unit is handling of the combination of the financial position; it involves the specific operation method about the accounting treatment. It is the feature of variety content, the trivial knowledge and easy to confuse. Using all kinds of multimedia teaching let the students participate in the process of learning, and let them master the knowledge the knowledge to ensure efficient classroom knowledge internalization.

The third unit is the compilation of the financial position, which is the core part of this chapter. This part mainly introduces the two different cases about the compilation of the enterprise: one situation is the compilation at the daily accounting report; another situation is the compilation before the daily accounting report. This unit requires students to use whole chapter knowledge to complete the compilation of statements and working sheets. The rich background knowledge, large amount of calculation, strong comprehensive and closely related to real environment, and all these called Problem-based Learning (PBL) [10]. PBL as the driving question as the starting point and guide, to set the learning into the question situation. Students need to use various abilities to master the knowledge implied behind the questions. And teachers should according to teaching purpose and combine with the actual cases to set the questions, and then adopt teaching methods combined with the self-exploration, the team learning, the mutual exchange and summative evaluation to dispel misunderstandings.

\section{Conclusion}

The flipped classroom overturns the process of knowledge and knowledge internalization, it has completely liberated the class, and creatively realized the combination of virtual and physical, it is beneficial to improve the teaching effects of the CIMA. We should understand that the flipped classroom increases the ability of self-learning and also it puts forward the higher request to teachers. It is not only need to focus more energy on pre-class, also need more keen power of observation and the stronger control at the while-class. The transformation of roles between teachers and students has together make up the win-win of the flipped classroom.

\section{Acknowledgements}

General Item of Humanities and Social Sciences of Education Department of Sichuan (2013SSB0665)

\section{References}

[1] MOSHER, BOB: Chief Learning Officer, Vol.15 (2016), NO.1, p.12.

[2] Pienta: Journal of Chemical Education, Vol.93 (2016) NO.1, p.1

[3] Marta Caligaris: Georgina Rodrorgin; Lorena Laugero. Procedia - Social and Behavioral Sciences,Vol. 217(2016),P.838. 
[4] Q.L.Zhang, A.C. Wang: Modern educational technology, (2014) NO.4, P.27. (In Chinese)

[5] Z.H.Wu: Communication of Finance and Accounting, (2014), 19: 48-50. (In Chinese)

[6] Fitzgerald, Lisa: Flipping heck! Flipping the classroom: pedagogical and budgetary drivers ompletely libe (Council of Academic Public Health Institutions Australia, Australia 2013),p. 20

[7] Deanna Dahlke Ojennus: Biochemistry and Molecular Biology Education, Vol.44 (2016) No.1, p. 20

[8] REYNA, JORGE: Training \& Development, Vol.42 (2015) NO.5, p.30

[9] Moran, Kristen1: Counselor Education and Supervision, Vol.54 (2015) NO.1, p.32

[10]Smith, Ben: Science Teacher, Vol.82(2015)NO.3, p.8 